\title{
Multimode interference photonic switches
}

\author{
Abdulaziz M. Al-hetar \\ Abu Sahmah M. Supa'at \\ Abu B. Mohammad \\ Ian Yulianti \\ Universiti Teknologi Malaysia \\ Photonics Technology Centre \\ Faculty of Electrical Engineering \\ 81310 Johor, Malaysia \\ E-mail: alhetar_aziz@yahoo.com
}

\begin{abstract}
Photonic switches are becoming key components in advanced optical networks due to their various applications in optical communication. One of the key advantages of photonic switches is the fact that they redirect or convert light without any optical to electronic conversions and vice versa. As one type of optical switch, multimode interference (MMI) switches have received more attention in recent years due to their significant role. The structure and operation principle of various types of MMI switches are introduced, and the recent progresses of $\mathrm{MMI}$ switches are also discussed. (c) 2008 Society of Photo-Optical Instrumentation Engineers. [DOI: 10.1117/1.3028349]
\end{abstract}

Subject terms: multimode interference (MMI); integrated optics; Mach-Zehnder interferometer (MZI); optical switch.

Paper 080547VRR received Jul. 10, 2008; revised manuscript received Oct. 1, 2008; accepted for publication Oct. 6, 2008; published online Nov. 26, 2008.

\section{Introduction}

In the beginning to the 21 st century, there has been an intense race in optical fiber communication systems. The transmission capacity using dense wavelength division multiplexing (DWDM) has been increased dramatically to terabits per second (Tbps). The deployed optical communication system is not constrained by the signal transmitting capacity, but by the exchange rate between the network nodes. It is analog to a highway with only a narrow entrance or exit and subsequently causes traffic jams.

Electronics switching is highly efficient in routing due to the mature and sophisticated logic circuit and data storage technology capability that has been studied extensively. However, electronics switching is highly dependent on data rate and protocol, which will result in the addition or replacement of electronics switching when upgrading systems. Additionally, optical signal has to be converted to electronic signal (O/E conversion) before electrically switching, and then after, converted back to optical (E/O conversion) form again. With increase in network capacity, electronics switching nodes do not have the capability to cope with the bit rate, hence causing an electronics bottleneck.

An optical add drop module $(\mathrm{OADM})^{1}$ using optical switches and wavelength multiplexer (MUX) shown in Fig. 1 has been designed to address this stringent limitation. The optical switches can selectively download the signal from the channel, upload the signal to the channel, or simply pass the signal through the OADM. This primarily depends on the working status of the optical switches - either in the cross or the bar state. Unlike any electrical exchange processors, optical switching enables routing of optical data signals without $\mathrm{O} / \mathrm{E}$ and $\mathrm{E} / \mathrm{O}$ conversion. Therefore, it is independent of data rate and data protocol, and it is meant primarily for more effective data transmission. This will greatly improve the system capacity and decrease the overall system cost, due to reduction in the amount of network equipment. There are many types of optical switches, such

0091-3286/2008/\$25.00 @ 2008 SPIE as micro-electro-mechanics system (MEMS) optical switches and optical waveguide switches [including the multimode interference (MMI) switches].

In recent years, multimode interference (MMI) couplers have attracted considerable interest due to their: unique characteristics such as compactness, ${ }^{2}$ relaxed fabrication tolerance, large optical bandwidth, ${ }^{3}$ and polarization insensitivity, when strongly guided structures are used. ${ }^{4,5}$ At the same time, this can be applicable in splitters and combiners, ${ }^{6}$ mode converters, ${ }^{7}$ and power splitters with arbitrary splitting ratio. ${ }^{8}$ Only recently, their use has been expanded from passive to active devices, and several photonic switches have been proposed using MMI effects. ${ }^{9-12}$

\section{Multimode Interference Switches}

The concept of multimode interference was first put forth by John Talbot in 1836, and the possibility of achieving self-imaging in uniform index slab waveguides was first suggested by Bryngdahl. ${ }^{13}$ As a result of self-images, the possibility of achieving a crossover of strip guides, a simple 3-dB directional coupler, and a filter (separating two wavelengths) was demonstrated by Ulrich and Ankele, ${ }^{14}$ but only since the early 1990s has the concept been studied in more detail. Key papers written by Soldano, Penning, et al.,6,15 analyzed the mathematics of the self-imaging phenomenon by calculating the coupling coefficients and predicting where multiple images can be found. Another key paper by Bachmann et al. ${ }^{16}$ in 1994 took this theory even further to calculate the phase relation between the input and the outputs, and outputs relative to each other. A convenient description for the phase inside the MMI region has been given by Heaton and Jenkins. ${ }^{17}$ Most MMI switches are based on the self-imaging principle as described in Secs. 2.1 and 2.2.2 (a property of multimode waveguide by which an input field profile is reproduced in single or multiple images at periodic intervals along the propagation direction of the guide, ${ }^{4}$ as shown in Fig. 2).

As it has been known that the input field profile $E(x, 0)$ imposed at $z=0$ will be decomposed into the modal field distribution $\phi_{v}(x)$ of all modes 


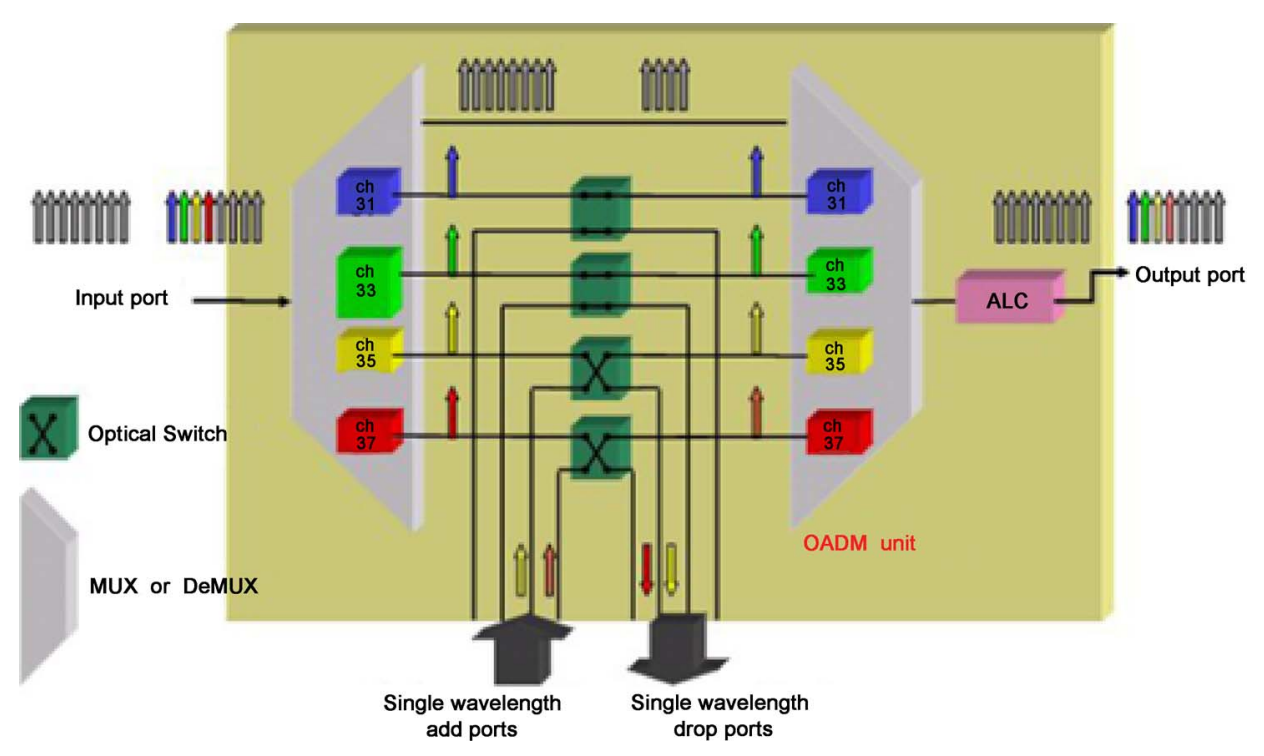

Fig. 1 OADM unit using optical switches and wavelength multiplexers.

$E(x, 0)=\sum_{m} C_{m} \phi_{m}(x)$,

the field profile at a distance $z=L$ can then be written for

$E(x, L)=\sum_{m} C_{m} \phi_{m}(x) \exp \left[j \frac{m(m+2) \pi}{3 L_{\pi}} L\right]$,

where $m$ is the mode number, and $L_{\pi}$ is the beat length of the two lowest-order modes. ${ }^{4}$ Therefore, we can change the field profile by modulating mode phases and obtain the desired output field.

\subsection{MMI-MZI Switches}

The general structure of tunable MMIs is based on the Mach-Zehnder interferometer (MZI) principle. A typical MMI-MZI is composed of an MMI power splitter with $N$ input ports, an MMI recombined with $N$ output ports, and several phase-shift arms with active regions as shown in the Fig. $3 .{ }^{18}$ The active region (electro- or thermo-optic region) is used to change the relative phases among the arms, which can realize the switching ${ }^{18-33}$ or tunable power splitting function at the outputs. ${ }^{22}$

Generally, the MZI switches are based on Y-junction, directional coupler and MMI. The Y-junction is large

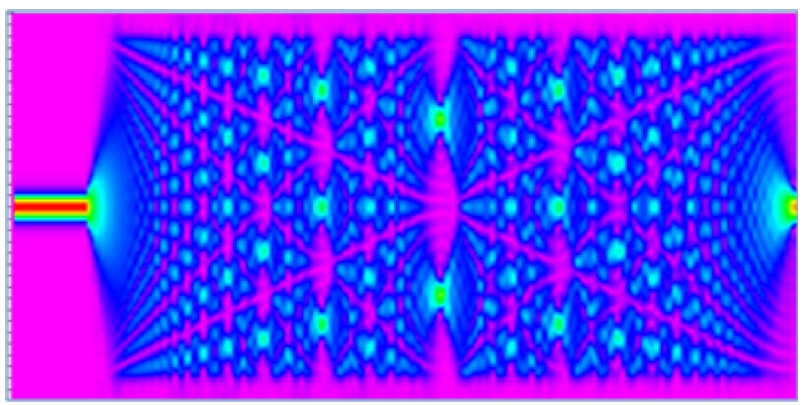

Fig. 2 Field distribution of MMI. and requires precise lithography at the waveguide intersection. ${ }^{32}$ On the other hand, directional couplers need tight $(\sim 0.1 \mu \mathrm{m})$ control of the waveguide dimensions since they exploit mode coupling between two waveguides that are close to each other. ${ }^{33}$ When compared with directional couplers, MMI couplers show better uniformity, polarization insensitivity, ${ }^{5}$ and bandwidth and fabrication tolerances ${ }^{3}$ and are more suitable for an MZI-type optical switch. Second, with a Y-junction, MMI couplers show better polarization insensitivity and fabrication tolerances.

A selection of realized MMI-MZI switches is summarized in Table 1. Nevertheless, the structure of MMI-MZI switches is similar to the traditional MZI in phase shifters, which clearly indicate that they also have poor fabrication tolerance, as does the MZI.

In
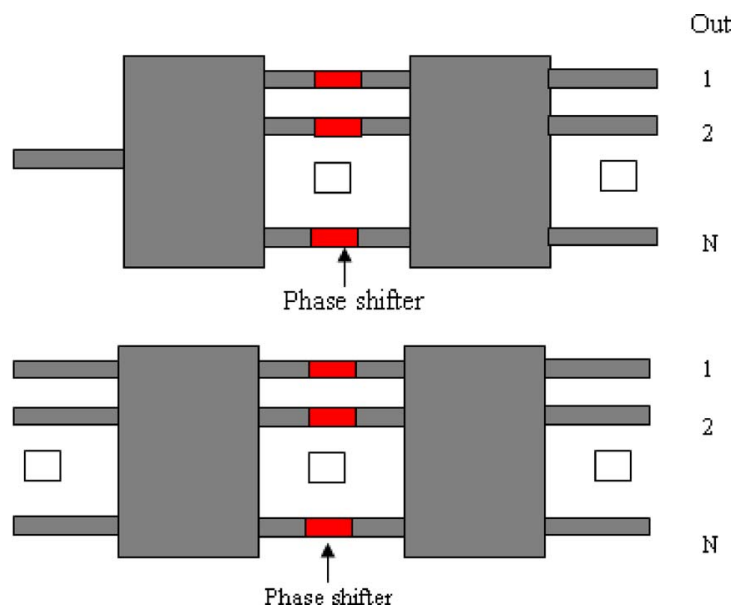

Fig. 3 Schematic layouts of a $1 \times N$ and $N \times N$ general MachZehnder interferometer, comprising MMI couplers as splitter/ combining elements, and waveguide phase shifter. 
Table 1 A selection of published MMI-MZI switches (TO=thermo-optic; $E O=$ electro-optic; $f-f=$ fiber to fiber; $\mathrm{SW}=$ switching time; $\mathrm{CT}=$ crosstalk; IL=insertion loss).

\begin{tabular}{|c|c|c|c|c|c|c|c|}
\hline $\mathrm{N} \times \mathrm{N}$ & Technology & $\begin{array}{l}\mathrm{CT}(\mathrm{dB}) \\
\text { cross/bar }\end{array}$ & $\mathrm{IL}(\mathrm{dB})$ & $\mathrm{SW}(\mu \mathrm{S})$ & $\begin{array}{l}\text { Power } \\
(\mathrm{mW})\end{array}$ & $\begin{array}{l}\text { Switching } \\
\text { technology }\end{array}$ & Reference \\
\hline $1 \times 2$ & $\mathrm{SiO}_{x} / \mathrm{SiO}_{2}$ & & & 222 & 19 & TO & 26 \\
\hline $2 \times 2$ & SOI & -23.4 & 1.8 & 30 & 20 & TO & 25 \\
\hline $2 \times 2$ & SOI & -17.1 & $2(f-f)$ & 60 & 35 & TO & 27 \\
\hline $2 \times 2$ & SOI & $-18.5 /-15$ & $14(f-f)$ & 8 & 45 & TO & 28 \\
\hline $4 \times 4$ & SOI & -16.5 & $17(f-f)$ & 15 & 88 & TO & 29 \\
\hline $2 \times 2$ & SOI & $-32 /-16$ & 3.4 & 3000 & 58 & TO & 31 \\
\hline $4 \times 4$ & InGaAsP & -15 & 5 & 0.2 & $0.5 \mathrm{~V}$ & EO & 19 \\
\hline $2 \times 2$ & InGaAsP & -21 & 4 & & 60 & TO & 34 \\
\hline $2 \times 2$ & $\mathrm{SiON} / \mathrm{SiO}_{2}$ & $-24 /-27$ & 3 & 3000 & 57 & TO & 35 \\
\hline $2 \times 2$ & InGaAIAs & $-30 /-20$ & $14.2(f-f)$ & & $0.7 \mathrm{~V}$ & EO & 20 \\
\hline $2 \times 2$ & $\mathrm{SiO}_{\mathrm{x}} / \mathrm{SiO}_{2}$ & -21 & 1 & 180 & 110 & TO & 21 \\
\hline $1 \times 4$ & $\begin{array}{l}\text { Polymer/ } \\
\mathrm{SiO}_{2}\end{array}$ & -6 & 0.65 & 3000 & $7 \mathrm{~mA}$ & TO & 23 \\
\hline $2 \times 2$ & $\begin{array}{l}\text { Polymer/ } \\
\mathrm{SiO}_{2}\end{array}$ & -20 & 4.1 & & & TO & 30 \\
\hline $2 \times 2$ & SOI & $-2 /-5$ & 8 & & 85 & TO/first using & 36 \\
\hline $2 \times 2$ & Polymer & $-33 /-31$ & & & 2.1 & TO & 37 \\
\hline
\end{tabular}

\subsection{Photonic Switch}

New compact structures for tunable MMIs have been carried out. The optical functions are realized by tuning the refractive index directly within different section of MMIs.

In the MMI photonic switch (MIPS), the index modulation (IM) region is located within the MMI section. According to the position of the IM, MIPS is classified as size modulated or image modulated.

\subsubsection{Size-modulated MMI switch}

The IM regions are located horizontal to the light propagation. In first configuration, the confinement guide region is created $^{10-12,38}$ to allow the light to pass through the region, as shown in Fig. 4.

Second, the width of the MMI region is varied by varying the refractive indices of the segments (IM regions) inside the MMI section, ${ }^{39}$ It is possible to use different interference phenomena (general, paired, and symmetric interference) in one device to achieve different switching states. If the width of the MMI regions is reduced by depressing the refractive index (by means of the electro-optic effect), the imaging locations will be changed. Thus, the switching of the input signal to different output ports may be possible. Figure 5 shows $3 \times 3$ MMI-switch of the same type. Electro-optic is highly effective to use in this type of MMI switch in comparison with thermo-optic.
Additionally, the power consumption is high due to the length of index modulation. This type of switch is very promising for future DWDM and optical cross connect (OXC) systems, due to its compactness and multifunctionality.

In

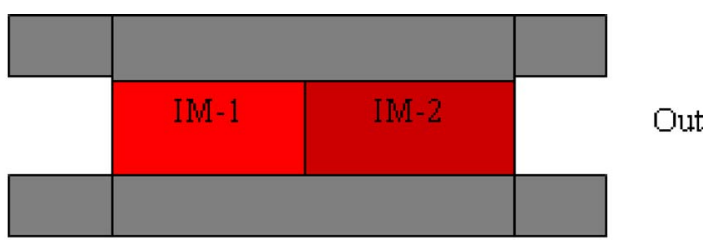

(a)

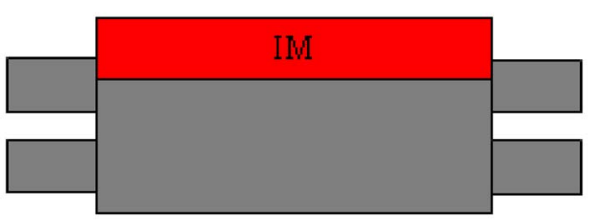

(b)

Fig. 4 (a) and (b) $2 \times 2 \mathrm{MMl}$ switch using a confinement guide region. 


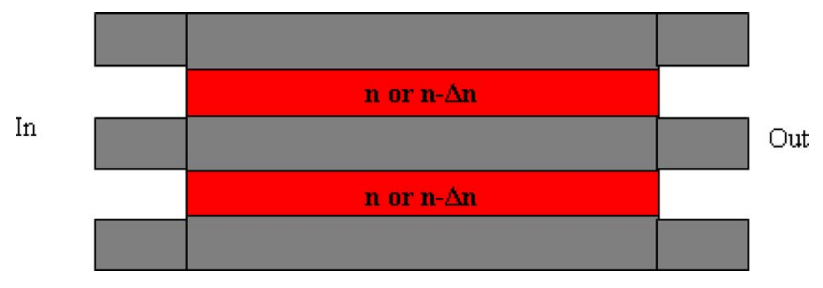

Fig. 5 Segmented MMI switch.

\subsubsection{Image-modulated MMI switch}

Switching is achieved by exploiting the fact that within an MMI, the input field is reproduced in single or multiple images at certain periodic intervals along the propagation direction of the light. ${ }^{13}$ The interference pattern of the selfimages in one interval can lead to the formation of new self-images in the next interval and subsequently to the output images. Consequently, the output image can be changed by modifying the refractive index around some selected spots within one interval of the MMI where such self-images occur. Modifying the refractive indices will lead to a new phase relation between the self-images at the next interval and with that to a modified output image. Light can then be directed to a specific output waveguide. This approach works properly as long as the refractive index change is entirely confined within the areas containing the principal self-images.

The first example of this configuration used the passive MMI coupler to select the splitter power ratio. ${ }^{40,41}$ After that, several photonic switches have been proposed using the IM inside the MMI section to modify the phase relation between the self-images. ${ }^{9,37,42-47}$ The switching mechanism of all these switches is the same-they operate by modifying the refractive index at specific areas within the MMI waveguide, which are collocated with the occurrence of multiple self-images. This change in the refractive index effectively alters the phase relation between the selfimages, which ultimately modifies the output image and switches the light between the output waveguides. Hence, this will eventually show more efficient switching capability. Figure 6 shows the structure of a $2 \times 2$ imagemodulated MMI switch. ${ }^{47}$ The index modulation region is located where two images are formed. For waveguide length equal to odd multiples of $L_{\pi}$, the phase shift between symmetric and asymmetric modes is an odd multiple of $\pi$, and the input image will be inverted. ${ }^{4}$ Introducing an additional phase shift of $\pi$ at one of two formed images will make the image switch to the other port. In the same way,

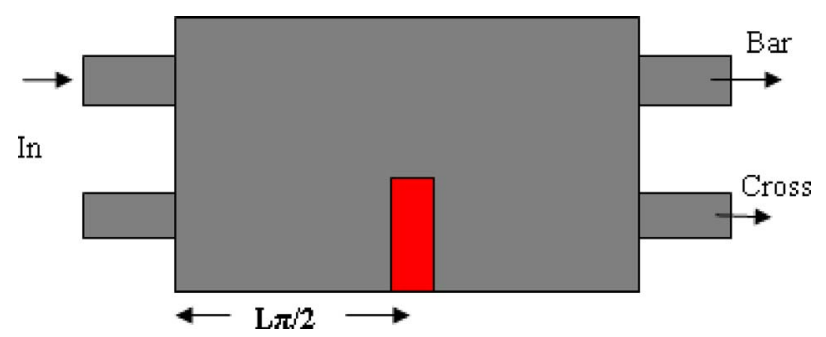

Fig. $62 \times 2$ image-modulated MMI switch.

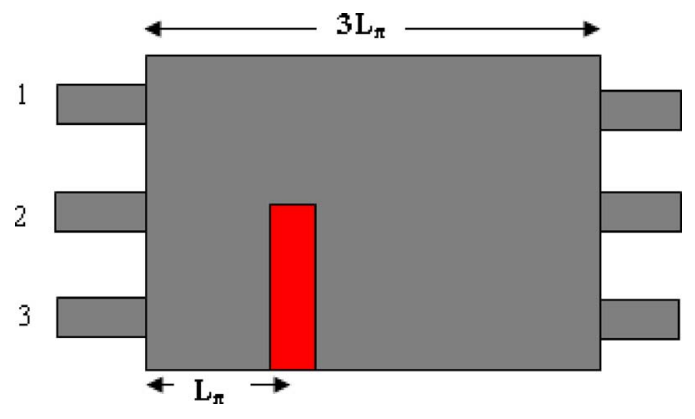

Fig. $73 \times 3$ image-modulated MMI switch.

the $3 \times 3$ (Ref. 43) and $\mathrm{N} \times \mathrm{N}$ (Ref. 9) image-modulated MMI switches have been demonstrated, as shown in Figs. 7 and 8.

Various types of switches based on MMI are summarized in Table 2 . In essence, their operations depend greatly on changing the refractive index of a particular region. It is difficult to say which switch type is best because their design aims are not exactly the same. For instance, some particularly emphasize high speed, while others emphasize compact structure.

Until recently, most of the reported MMI-MZI switches are based on electro-optic effect, current injection, and thermo-optic, while the MMI switches are based on electrooptic and current injection because the index modulation region is accurately controlled by the electric field without the effect of the other regions inside the MMI region. Even the reported MMI-MZI switches based on thermo-optic are unequal of crosstalk in the cross and bar state, due to the thermal diffusion from a heated arm to a nonheated arm in single-mode waveguides. It is important to investigate for a way to restrict lateral thermal diffusion when thermo-optic is used in this type of switch.

Recently, lateral thermal diffusion has been conquered when thermo-optic is used in MMI and MMI-MZI switches ${ }^{48,49}$ by introducing a ridge in the silicon substrate. The purpose behind this change to the MMI and intermediate single-mode waveguide structures for MMI and MMI-MZI switches, respectively, was to localize the heating. Thus, the switch performances of the devices have been improved.

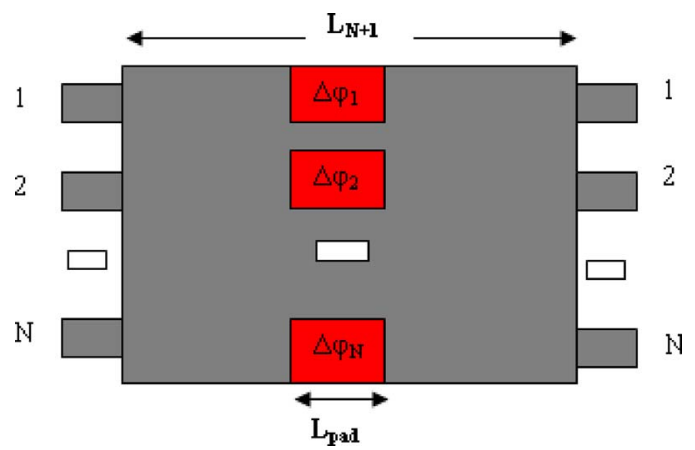

Fig. $8 \mathrm{~N} \times \mathrm{N}$ image-modulated MMl switch. 
Table 2 A selection of published MMI switches (PDL=polarization dependence loss; SW=switching time; $C T=$ crosstalk; IL=insertion loss).

\begin{tabular}{|c|c|c|c|c|c|c|c|c|c|c|}
\hline \multirow[b]{3}{*}{$\mathrm{N} \times \mathrm{N}$} & \multirow[b]{3}{*}{ Technology } & \multicolumn{3}{|c|}{ Device dimension } & \multicolumn{5}{|c|}{ Optical switch performance } & \multirow[b]{3}{*}{ Reference } \\
\hline & & \multirow[b]{2}{*}{$\begin{array}{l}\mathrm{MMI} \\
\mathrm{W} \times \mathrm{L}\end{array}$} & \multicolumn{2}{|c|}{$\mathrm{Ml}$} & \multirow[b]{2}{*}{$\begin{array}{l}\mathrm{CT} \\
(\mathrm{dB})\end{array}$} & \multirow[b]{2}{*}{$\begin{array}{l}\mathrm{IL} \\
(\mathrm{dB})\end{array}$} & \multirow[b]{2}{*}{$\begin{array}{l}\mathrm{ST} \\
(\mu \mathrm{S})\end{array}$} & \multirow[b]{2}{*}{$\begin{array}{l}\text { PDL } \\
(\mathrm{dB})\end{array}$} & \multirow[b]{2}{*}{$\begin{array}{l}\text { Power } \\
(\mathrm{mW})\end{array}$} & \\
\hline & & & $W \times L$ & Direction & & & & & & \\
\hline $1 \times 2$ & InGaAsP/InP & $8 \times 540$ & $\begin{array}{l}4 \times 540 \\
8 \times 540\end{array}$ & $\mathrm{H}$ & $\begin{array}{l}-11 \\
-20\end{array}$ & & & & $26 \mathrm{~mA}$ & 48 \\
\hline $3 \times 3$ & InGaAsP/InP & $12 \times 129$ & $\begin{array}{c}4 \mathrm{IM} \\
6 \times 24\end{array}$ & V & -20 & & & & & 42 \\
\hline $3 \times 3$ & $\operatorname{lnGaAsP} / \ln P$ & $\begin{array}{l}12 \times 648 \\
8 \times 300\end{array}$ & $\begin{array}{c}3 \mathrm{IM} \\
6 \times 24\end{array}$ & v & -25 & & & & & 43 \\
\hline $1 \times 2$ & $\ln G a A s P / \ln P$ & $8 \times 599$ & $6 \times 599$ & $\mathrm{H}$ & $\begin{array}{l}-8 \\
-10\end{array}$ & & & & $20 \mathrm{~mA}$ & 10 \\
\hline $2 \times 2$ & InGaAsP/InP & $8 \times 599$ & $6 \times 599$ & $\mathrm{H}$ & $\begin{array}{c}-8 \\
-13\end{array}$ & & & & $20 \mathrm{~mA}$ & 10 \\
\hline $1 \times 2$ & Polymer (ZPU) & $48 \times 3600$ & $16 \times 3600$ & $\mathrm{H}$ & $\begin{array}{l}-20 \\
-20\end{array}$ & $\begin{array}{l}0.6 \\
0.9\end{array}$ & 4000 & $\begin{array}{l}0.3 \\
0.6\end{array}$ & 22 & 12 \\
\hline $2 \times 2$ & InGaAsP/InP & $18 \times 998$ & $\begin{array}{c}2 \mathrm{IM} \\
3.5 \times 28\end{array}$ & $\mathrm{~V}$ & $<20$ & & 0.001 & & & 44 \\
\hline $1 \times 2$ & Sol-gel & $36 \times 2015$ & $\begin{array}{c}1 \mathrm{IM} \\
4-10 \times 2015\end{array}$ & $\mathrm{H}$ & $\begin{array}{l}-38 \\
-34\end{array}$ & $\begin{array}{l}0.94 \\
1.09\end{array}$ & & 0.4 & 4 & 38 \\
\hline $1 \times 2$ & Polymer/Sio2 & $50 \times 1321$ & $\begin{array}{c}3 \mathrm{IM} \\
4 \times 660.5\end{array}$ & $\mathrm{H}$ & -28 & 1 & & & & 11 \\
\hline $2 \times 2$ & Polymer & $30 \times 3506$ & $\begin{array}{c}1 \mathrm{IM} \\
4 \times 100\end{array}$ & $\mathrm{H}$ & $\begin{array}{l}-39 \\
-39\end{array}$ & & 0.8 & & 1.35 & 49 \\
\hline
\end{tabular}

\section{Conclusion}

MMI switches are very promising for their particular advantages, such as compactness and relaxed fabrication tolerance. With the improvement of switching performance, MMI switches will play an important role in optical communications.

\section{Acknowledgments}

The authors would like to thank the Ministry of Science, Technology, and Innovation of Malaysia (MOSTI) for sponsoring this work under Project No. 01-01-06-SF0488.

\section{References}

1. M. Okuno, "Highly integrated PLC-type optical switches for OADM and OXC systems," in Proc. Optical Fiber Communications Conf. vol. 1, pp. 169-170, IEEE (2003).

2. L. H. Spiekman, Y. S. Oei, E. G. Metaal, F. H. Groen, I. Moerman, and M. K. Smit, "Extremely small multimode interference couplers and ultra short bends on InP by deep etching," IEEE Photonics Technol. Lett. 6(8), 1008-1010 (1994).

3. P. A. Besse, M. Bachmann, H. Melchior, L. B. Soldano, and M. K. Smit, "Optical bandwidth and fabrication tolerances of multimode interference couplers," J. Lightwave Technol. 12(6), 1004-1009 (1994).

4. L. B. Soldano and Erik C. M. Pennings "Optical multimode interference devices based on self-imaging: principles and applications," $J$ Lightwave Technol. 13(4), 615-627 (1995).

5. J. M. Heaton, R. M. Jenkins, D. R. Wight, J. T. Parker, J. C. H Birheck, and K. P. Hilton, "Novel 1-to-N way integrated optical beam splitters using symmetric mode mixing in GaAs/AlGaAs multimode waveguides," Appl. Phys. Lett. 61(15), 1754-1756 (1992).
6. L. B. Soldano, F. B. Veerman, M. K. Smit, B. H. Verbeck, A. H Dubost, and E. C. M. Pennings, "Planar monomode optical couplers based on multimode interference effects," J. Lightwave Technol. 10(12), 1843-1850 (1992)

7. J. Leuthold, J. Eckner, E. Gamper, P. A. Besse, and H. Melchior, "Multimode interference couplers for the conversion and combining of zero and first-order modes," J. Lightwave Technol. 16(7), 12281239 (1998).

8. Q. Lai, M. Bachmann, W. Hunziker, P. A. Besse, and H. Melchior, "Arbitrary ratio power splitters using angled silica on silicon multimode interference couplers," Electron. Lett. 32(17), 1576-1577 (1996).

9. J. Leuthold, and C. H. Joyner, "Multimode interference couplers with tunable power splitting ratios," J. Lightwave Technol. 19(5), 700-706 (2001).

10. S. Nagai, G. Morishima, H. Inayoshi, and K. Utaka, "Multimode interference photonic switches (MIPS)," J. Lightwave Technol. 20(4), 675-681 (2002).

11. M. H. Ibrahim, M. Koy, N. M. Kassim, and A. B. Mohammad "A novel $1 \times 2$ Thermo-optic multimode interference switch structure based on BCB 4024-40 polymer on silica," CHIN Phys. Lett. 23(10), 2796-2798 (2006).

12. F. Wang, J. Yang, L. Chen, X. Jiang, and M. Wang, "Optical switch based on multimode interference coupler," IEEE Photonics Technol. Lett. 18(2), 421-423 (2006).

13. O. Bryngdahl, "Image formation using self-imaging techniques," $J$. Opt. Soc. Am. 63(4), 416-419 (1973).

14. R. Ulrich and G. Ankele, "Self-imaging in homogeneous planar optical waveguides," Appl. Phys. Lett. 27(6), 337-339 (1975).

15. E. C. M. Pennings, R. van Roijen, M. J. N. Van Stralen, P. J. de Waard, R. G. M. P. Koumans, and B. H. Verbeek "Reflection properties of multimode interference devices," IEEE Photonics Technol. Lett. 6(6), 715-718 (1994).

16. M. Bachmann, P. A. Besse, and H. Melchior, "General self-imaging properties in $\mathrm{N} \times \mathrm{N}$ multimode interference couplers including phase relations," Appl. Opt. 33(18), 3905-3911 (1994). 
17. J. M. Heaton and R. M. Jenkins, "General matrix theory of selfimaging in multimode interference (MMI) couplers," IEEE Photonics Technol. Lett. 11(2), 212-214 (1999).

18. R. M. Jenkins, J. M. Heaton, D. R. Wight, J. T. Parker, J. C. H. Birbeck, G. W. Smith, and K. P. Hilton, "Novel $1 \times N$ and $\mathrm{N} \times \mathrm{N}$ integrated optical switches using self-imaging multimode GaAs/ AIGaAs waveguides," Appl. Phys. Lett. 64(6), 684-686 (1994).

19. R. Krähenbühl, R. Kyburz, W. Vogt, M. Bachmann, T. Brenner, E. Gini, and H. Melchior, "Low-loss polarization-insensitive InPInGaAsP optical space switches for fiber optical communication," IEEE Photonics Technol. Lett. 8(5), 632-634 (1996).

20. N. Yoshimoto, Y. Shibata, S. Oku, S. Kondo, Y. Noguchi, K. Wakita, and M. Naganum "Fully polarisation independent Mach-Zehnder optical switch using a lattic-ematched InGaAIAs/lnAIAs MQW and high mesa waveguide structure," Electron. Lett. 32(15), 1368-1369 (1996).

21. Q. Lai, W. Hunziker, and H. Melchior "Low-power compact $2 \times 2$ thermooptic silica on silicon waveguide switch with fast response," IEEE Photonics Technol. Lett. 10(5), 681-683 (1998).

22. N. S. Lagali, M. R. Paiam, R. I. MacDonald, K. Workoff, and A. Driessen, "Analysis of generalized Mach-Zehnder interferometers for variable-ratio power splitting and optimized switching," J. Lightwave Technol. 17(12), 2542-2250 (1999).

23. J. P. Hnatiw, R. G. DeCorby, J. N. McMullin, C. Callende, and R. I. MacDonald, "A multimode thermo-optic polymer switch for incorporation in a $4 \times 4$ hybrid integrated optoelectronic switch matrix," in Proc. Electrical and Computer Engineering Conf., IEEE, vol. 2, pp. 645-650 (1999).

24. M. P. Earnshaw, J. B. D. Soole, M. Cappuzzo, L. Gomez, E. Laskowski, and A. Paunescu, "Compact, low-loss $4 \times 4$ optical switch matrix using multimode interferometers," Electron. Lett. 37(2), 115-116 (2000)

25. Z.-T. Wang, J.-S. Xia, Z.-C. Fan, S.-W. Chen, and J.-Z. Yu, "Fabrication of thermo-optic switch in silicon-on-insulator," Chin. Phys. Lett. 20(12), 2185-2187 (2003).

26. J.-K. Hong and S.-S. Lee, "Reduced-power consuming silica-based compact $1 \times 2$ MZI thermo-optic switch using MMI couplers," $J$. Korean Phys. Soc. 45(1), 84-87 (2004).

27. J. Xia, J. Yu, Z. Wang, Z. Fan, and S. Chen, "Low power $2 \times 2$ thermo-optic SOI waveguide switch fabricated by anisotropy chemical etching," Opt. Commun. 232, 223-228 (2004).

28. J. Liu, J. Yu, S. Chen, and J. Xia, "Fabrication and analysis of 2 $\times 2$ thermo-optic SOI waveguide switch with low power consumption and fast response by anisotropy chemical etching," Opt. Commun. 245, 137-144 (2005)

29. D. Yang, Y. Li, F. Sun, S. Chen, and J. Yu, "Fabrication of a $4 \times 4$ strictly nonblocking SOI switch matrix," Opt. Commun. 250, 48-53 (2005).

30. K. Masuda, A. Tate, and H. Tsuda, "A nonel $2 \times 2$ multi-arm type of optical switch using multimode interference couplers," IEICE Electron. Express 3(9), 191-196 (2006).

31. Z. Wan, Y. Wu, and S. Li, "Experimental research on an integrated thermooptic switch based on multimode interference couplers," Electric. Electron. Eng. 2(1), 78-82 (2007).

32. U. Siebel, R. Hauffe, and K. Petermann, "Crosstalk-enhanced polymer digital optical switch based on a W-shape," IEEE Photonic Technol. Lett. 12(1), 40-41 (2000).
33. G. Müller, L. Stoll, G. Schulte-Roth, and U. Wolff, "Low current plasma effect optical switch on InP," Electron. Lett. 26(2), 115-116 (1990).

34. S. S. Agashe, K.-T. Shiu, and S. R. Forrest, "Compact polarizationinsensitive InGaAsP-InP $2 \times 2$ optical switch," IEEE Photonics Technol. Lett. 17(1), 52-54 (2005).

35. N. S. Lagali, "The general Mach-Zehnder interferometer using multimode interference coupler for optical communication network," PhD Thesis, University of Alberta (2001).

36. U. Fischer, T. Zinke, and K. Petermann, "Integrated optical waveguide switches in SOI," in Proc. IEEE Intl. SO1 Conference, pp. 141-142, IEEE (1995).

37. A. M. Al-hetar, I. Yulianti, A. S. M. Supa'at, and A. B. Mohammad, "Thermo-optic multimode interference switches with air and silicon trenches," Opt. Commun. 281, 4653-4657 (2008).

38. X. Wu, L. Liu, Y. Zhang, D. Li, W. Wang, and L. Xu, "Low electric power drived thermo-optic multimode interference switches with tapered heating electrodes," Opt. Commun. 258, 135-143 (2006).

39. P. Zhao, J. Chrostowski, and W. J. Bock, "Novel multimode coupler switch," Microwave Opt. Technol. Lett. 17(1), 1-7 (1998).

40. Q. Lai, M. Bachmann, W. Hunziker, P. A. Besse, and H. Melchior, "Arbitrary ratio power splitters using angled silica on silicon multimode interference," Electron. Lett. 32(17), 1576-1577 (1996).

41. D. S. Levy, Y. M. Li, R. Scarmozzino, and R. M. Osgood Jr., "A multimode interference-based variable power splitter in GaAsAlGaAs," IEEE Photonics Technol. Lett. 9(10), 1373-1375 (1997).

42. M. Yagi, S. Nagai, H. Inayoshi, and K. Utaka, "Versatile multimode interference photonic switches with partial index-modulation regions," Electron. Lett. 36(5), 533-534 (2000).

43. K. Utaka, S. Nagai, M. Yagi, H. Inayoshi, and G. Morishima, "New structure of multimode interference photonic switch with partial index modulation regions (MIPS-P)," in Proc. Asia-Pacific Conf. Comm./OptoElec. Communications Conf. '99, vol. 1, pp. 469-470 IEEE (1999).

44. D. A. May-Arrioja, N. Bickel, and P. Likamwa, "Robust $2 \times 2$ multimode interference optical switch," Opt. Quantum Electron. 38(7), 557-566 (2006).

45. D. A. May-Arrioja, P. LiKamWa, C. Velásquez-Ordóñez, and J. J. Sánchez-Mondragón, "Tunable multimode interference coupler," Electron. Lett. 43(13), 714-715 (2007).

46. K. Utaka, "Semiconductor photonic switching devices for wavelength division multiplexing systems," in Photonics Based on Wavelength Integration and Manipulation pp. 161-174, IPAP Books 2 (2005).

47. T. Ishikawa, S. Kumai, K. Utaka, H. Amanai, K. Kurihara, and K. Shimoyama, "High-performance of InAlGaAs/InAlAs/InP multimode interference photonic switch with partial index-modulation region (MIPS-P)," IEICE Electron. Express 2(23), 578-582 (2005).

48. S. Nagai, N. Kogure, G. Morishima, and K. Utaka, "Proposal of novel InGaAsP/InP Multimode interference photonic switches," in Proc. Int. Conf. on Indium Phosphide and Related Materials, pp. 691-694, IEEE (1998)

49. A. M. Al-hetar, A. S. M. Supa'at, A. B. Mohammad, and I. Yulianti, "Crosstalk improvement of a thermo-optic polymer waveguide MZIMMI switch,” Opt. Commun. 281, 5764-5767 (2008).

Biographies and photographs of the authors not available. 